\title{
Rekrutmen Dan Pengelolaan Tim Kerja Yang Efektif Terhadap Kinerja Karyawan
}

\author{
Lilis Nurjanah, Supramono, Rachmatullaily
}

Fakultas Ekonomi dan Bisnis Universitas Ibn Khaldun Bogor, Indonesia supramonouika@gmail.com

\begin{abstract}
Abstrak
Keberhasilan suatu perusahaan tergantung pada proses rekrutmen, pengelolaan tim kerja yang efektif dan kinerja karyawan. Tujuan penelitian ini untuk mengetahui:(1) Pengaruh antara rekrutmen terhadap kinerja karyawan pada PT. Indoglobal Galang Pamitra Bogor. (2) Pengaruh antara pengelolaan tim kerja yang efektif terhadap kinerja karyawan pada PT. Indoglobal Galang Pamitra Bogor. (3) Pengaruh secara bersama-sama variabel rekrutmen dan pengelolaan tim kerja yang efektif terhadap kinerja karyawan pada PT. Indoglobal Galang Pamitra Bogor. Penelitian ini dilaksanakan di PT Indoglobal Galang Pamitra Bogor pada karyawan bagian gudang. Jumlah sampel dan populasi 70 orang. Metode penelitian digunakan adalah metode kuantitatif dan analisis inferensial. Hasil penelitian menunjukkan bahwa:(1)Terdapat pengaruh yang kuat dan positif antara variabel rekrutmen dengan kinerja karyawan. (2) Terdapat pengaruh yang sangat kuat dan positif antara variabel tim kerja dengan kinerja karyawan. (3) Terdapat pengaruh yang kuat dan positif antara variabel rekrutmen dan tim kerja bersama-sama terhadap variabel kinerja karyawan. Diharapkan penelitian ini dapat memberikan manfaat dalam proses rektrutmen dan pengelolaan tim kerja di PT.Indoglobal Galang Pamitra Bogor.
\end{abstract}

Kata Kunci: Rekrutmen, Tim Kerja,Efektif dan Kinerja

\section{Pendahuluan}

Latar Belakang

Rekrutmen sebagai gerbang awal

dalam menyeleksi calon karyawan

perlu diperhatikan oleh manager.

Karena karyawan sebagai human

capital akan sanngat berpengaruh

pada produktifitas perusahaan

Pentingnya perusahaan menerapkan kualifikasi calon karyawan dan prinsip rekrutmen the right man and the right place agar mampu mendapatkan karyawan sesuai dengan kebutuhan perusahaan.

Sebagai salah satu perusahaan yang menerapkan sistem kerja out sourcing, PT.Indoglobal Galang Pamitra perlu membuat perjanjian kontrak kerja pada karyawan untuk 
mengantisipasi karyawan yang tibatiba melakukan pemutusan hubungan kerja. Karena pentingnya pelaksanaan program rekrutmen maka diharapkan pihak manager dapat mengatur dengan baik kegiatan tersebut dan selektif dalam memilih karyawan yang akan bergabung dengan perusahaan. Sehingga nantinya dapat menjaring karyawan yang memiliki kepribadian baik dan kemampuan sesuai kebutuhan perusahaan.

Indikator lain yang dapat menentukan keberhasilan perusahaan adalah pengelolaan tim kerja. Manager perlu membentuk tim-tim kecil pada setiap bagian untuk memudahkan dalam pendelegasian tugas, proses pengontrolan dan pengawasan pengawasan pekerjaan. Selain itu di perusahaan di perlukan dua orang atau lebih untuk bekerja sama guna menciptakan dan membentuk suatu nilai dengan pemahaman bahwa nilai tersebut dapat tercapai secara efisien apabila keduanya bekerja sama daripada bekerja secara individu.

Tentunya dalam pembentukan tim tersebut akan mendapatkan hambatan dari pihak internal dan eksternal perusahaan yang harus diantisipasi dengan melakukan peningkatan kerja sama, bertukar pikiran ,kesepahaman visi dan misi, menumbuhkan sikap saling menghargai. Dengan adanya pengelolaan tim tersebut nantinya akan terbentuk suatu tim yang solid yang dapat meningkatkan semangat kerja karyawan sehingga target yang ditetapkan perusahaan dapat tercapai. Sehingga dengan adanya pembentukan tim kerja akan berpengaruh pada kinerja karyawan PT. Indoglobal Galang Pamitra Bogor.

Kinerja merupakan kesediaan individu atau kelompok untuk menyelesaikan tanggung jawabnya dengan sebaik-baiknya untuk mencapai hasil yang sempurna. Kinerja karyawan dipengaruhi oleh 
berbagai faktor yaitu faktor

kemampuan, motivasi dalam bekerja, kompensasi yang diterima, pengontrolan \& pengawasan oleh pimpinan Faktor-faktor diatas perlu diperhatikan oleh para manager sebagai bahan untuk evaluasi kinerja karyawan.

\section{Perumusan Masalah}

Perumusan masalah dalam penelitian ini adalah sebagai berikut:

1. Apakah terdapat pengaruh rekrutmen terhadap kinerja karyawan pada PT. Indoglobal Galang Pamitra Bogor?

2. Apakah terdapat pengaruh pengelolaan tim kerja yang efektif terhadap kinerja karyawan PT. Indoglobal Galang Pamitra Bogor?

3. Apakah terdapat pengaruh rekrutmen dan pengelolaan tim kerja yang efektif secara bersamasama terhadap kinerja karyawan PT. Indoglobal Galang Pamitra Bogor?

\section{Tujuan dan Manfaat Penelitian}

\section{Tujuan Penelitian :}

1. Untuk mengetahui besarnya pengaruh antara rekrutmen dan pengelolaan tim kerja yang efektif terhadap kinerja karyawan pada PT. Indoglobal Galang Pamitra Bogor.

2. Untuk mengetahui keeratan hubungan antara rekrutmen dan pengelolaan tim kerja yang efektif terhadap kinerja karyawan pada PT. Indoglobal Galang Pamitra Bogor.

3. Untuk mengetahui faktor yang lebih dominan antara rekrutmen dan pengelolaan tim kerja yang efektif terhadap kinerja karyawan pada PT. Indoglobal Galang Pamitra Bogor.

\section{Manfaat Penelitian :}

1. Manfaat Bagi Penulis

Penelitian ini diharapkan dapat bermanfaat bagi penulis untuk menambah pemahaman berkenaan manajemen di Perseoran Terbuka (PT) berkaitan dengan proses rekrutmen dan pengelolaan tim 
kerja yang efektif terhadap kinerja karyawan. Pemahaman ini diharapkan dapat diterapkan dalam kehidupan dan tempat kerja penulis.

2. Kegunaan Akademis

Penelitian ini diharapkan

memberikan penambahan ilmu pengetahuan dan informasi yang dapat digunakan sebagai referensi dalam pengembangan penelitian selanjutnya.

3. Manfaat Bagi Perusahaan

Hasil dari penelitian yang diperoleh diharapkan dapat digunakan PT. Indoglobal Galang Pamitra. Bogor sebagai bahan informasi dalam melaksanakan program rekrutmen dan pengelolaan tim kerja yang efektif untuk meningkatkan kinerja karyawan.

\section{Metode Penelitian}

Jenis Penelitian

Dalam penelitian ini penulis menggunakan metode kuantitatif dan analisis inferensial untuk menganalisis pengaruh rekrutmen dan pengelolaan tim kerja yang efektif terhadap kinerja karyawan pada PT.Indoglobal Galang Pamitra di Bogor. Metode penelitian kuantitatif yang dikemukakan Sugiyono (2015:8) yaitu: "Metode penelitian yang berlandaskan pada filsafat positivisme, digunakan untuk meneliti pada populasi atau sampel tertentu pengumpulan data menggunakan instrumen penelitian, analisis data bersifat kuantitatif / statistik, dengan tujuan untuk menguji hipotesis yang telah ditetapkan.

\section{Tempat dan Waktu penelitian}

Penelitian ini dilaksanakan pada tanggal 20 April - 28 Juni 2018, dengan obyek penelitian pada karyawan bagian gudang PT. Indoglobal Galang Pamitra yang berada di Bogor Baru Blok CI No 10 Tegallega. 
Populasi dan Sampel

Dalam Silean

(2018:87)

Populasi (notasi N) adalah

"keseluruhan dari objek atau individu

yang memiliki karakteristik (sifat-

sifat) tertentu yang akan diteliti”.

Populasi disebut juga dengan

universum (universal) yang berarti

keleruhan dapat berupa benda hidup

atau benda mati. Populasi dan sampel

yang digunakan dalam penelitian ini

adalah 70 orang karyawan PT.

Indoglobal Galang Pamitra-Bogor.

Metode Pengumpulan Data

Metode pengumpulan data dalam penelitian ini adalah:

1. Observasi

2. Wawancara

3. Angket

4. Studi Pustaka

Metode Analisis Data

Uji Validitas

Menurut Silaen (2018:117)

"validitas adalah keabsahan atau

tingkat kecocokan alat ukur untuk pengukuran, yang benar-benar cocok mengukur sesuatu yang sedang diukur”.

\section{Uji Reliabilitas}

Menurut

Sujarweni

(2014:85), $\quad$ uji $\quad$ realibilitas

merupakan ukuran suatu kestabilan

dan konsistensi responden dalam

menjawab hal yang berkaitan

dengan

konstruk-konstruk

pertanyaan yang merupakan

dimensi suatu variabel dan disusun

dalam bentuk kuesioner.

\section{Uji Normalitas Data}

Menurut Sujarweni (2015:

52) “Uji ini dilakukan sebelum data-data diolah berdasarkan

model-model penelitian. Uji normalitas ini bertujuan untuk mengetahui distribusi data dalam variabel yang akan digunakan dalam penelitian”

\section{Uji Homogenitas}

“Uji homogenitas adalah pengujian mengenai sama tidaknya 
variansi-variansi dua buah distribusi atau lebih. Uji homogenitas bertujuan untuk mengetahui data dalam variabel $\mathrm{X}$ dan $\mathrm{Y}$ bersifat homogency atau tidak" menurut

(Edi Riadi 2016:127)

\section{Uji Liniearitas}

Uji liniearitas digunakan untuk mengetahui apakah variabel bebas dan terikat dalam penelitian ini memiliki hubungan yang liniear. Sujarweni (2015:56) Uji liniearitas untuk melihat spesifikasi model yang digunakan benar atau tidak.

\section{Analisis Regresi}

Regresi yang
peramalan, merupakan
analisis statistik hubungan yang
digunakan untuk meramalkan atau
memeperkirakan nilai dari suatu
variabel dalam hubungannya
dengan variabel lain melalui
persamaan garis regresi. Regresi
linear dapat berupa regresi linear

sederhana dan regresi linear berganda.

\section{Analisis Korelasi}

Analisis korelasi dengan

menggunakan uji statistik

dimaksudkan untuk mengukur derajat korelasi dari dua variabel, atau untuk mengetahui signifikantidaknya hubungan variabel independen dengan variabel dependen dalam Silaen (2018:222).

\section{Koefisien Determinasi}

Koefisien determinasi (KD) juga disebut koefisien penentu (KP) yaitu perubahan variabel dependen (variabel Y) yang disebabkan variabel independen (variabel X) adalah sebesar kuadrat koefisien korelasi $\left(r^{2}\right)$. Koefisien determinasi ini menjelaskan besarnya persentase pengaruh variabel $\mathrm{x}$ terhadap naikturunnya nilai variabel $\mathrm{Y}$, sedangkan sisanya atau selisihnya dari 100\% adalah pengaruh yang disebabkan oleh faktor lainnya yang 
tidak diteliti, dalam Silaen, hitung, proses uji t identik dengan Uji

$(2018: 372)$

\section{Uji Hipotesis (Uji T dan Uji F)}

Uji $t$ dikenal dengan uji parsial, yaitu untuk menguji bagaimana pengaruh masing-masing variabel bebasnya secara sendirisendiri terhadap variabel terikatnya. Uji ini dapat dilakukan dengan mambandingkan $\mathrm{t}$ hitung dengan $\mathrm{t}$ tabel atau dengan melihat kolom signifikansi pada masing-masing $t$
F.

Uji $\quad F \quad$ dikenal dengan Uji serentak atau uji Model / Uji Anova, untuk melihat bagaimana pengaruh semua variabel bebasnya secara bersamasama terhadap variabel terikatnya. Atau untuk menguji apakah model regresi yang kita buat signifikan atau tidak signifikan.

\section{Pembahasan}

\section{Hasil Penelitian Uji Validitas}

Tabel 4.6

Hasil Uji Validitas Variabel Rekrutmen (X

\begin{tabular}{|c|c|c|c|}
\hline No Item & rxy & r tabel 5\% & Keterangan \\
\hline X1_1 & 0,578 & 0,235 & Valid \\
\hline X1_2 & 0,721 & 0,235 & Valid \\
\hline X1_3 & 0,724 & 0,235 & Valid \\
\hline X1_4 & 0,697 & 0,235 & Valid \\
\hline X1_5 & 0,716 & 0,235 & Valid \\
\hline X1_6 & 0,716 & 0,235 & Valid \\
\hline X1_7 & 0,740 & 0,235 & Valid \\
\hline X1_8 & 0,696 & 0,235 & Valid \\
\hline X1_9 & 0,714 & 0,235 & Valid \\
\hline X1_10 & 0,601 & 0,235 & Valid \\
\hline X1_11 & 0,681 & 0,235 & Valid \\
\hline X1_12 & 0,614 & 0,235 & Valid \\
\hline X1_13 & 0,763 & 0,235 & Valid \\
\hline X1_14 & 0,620 & 0,235 & Valid \\
\hline X1_15 & 0,1516 & 0,235 & Valid \\
\hline
\end{tabular}


Sumber: Aplikasi komputer

Berdasarkan tabel $\quad 4.6 \quad$ Berikut tabel hasil uji validitas keputusan yang diambil bahwa untuk variabel tim kerja $\left(\mathrm{X}_{2}\right)$.

variabel rekrutmen $\left(\mathrm{X}_{1}\right)$, dengan 15

pertanyaan memiliki nilai $r$ hitung $>$

$\mathrm{r}_{\text {tabel. }}$ 0,235 . Sehingga semua item

pertanyaan dinyatakan valid.

Tabel 4.8 Hasil Uji Validitas Tim Kerja $\left(\mathrm{X}_{2}\right)$

\begin{tabular}{|c|c|c|c|}
\hline No Item & rxy & r tabel 5\% & Keterangan \\
\hline X2_1 & 0,729 & 0,235 & Valid \\
\hline X2_2 & 0,732 & 0,235 & Valid \\
\hline X2_3 & 0,829 & 0,235 & Valid \\
\hline X2_4 & 0,793 & 0,235 & Valid \\
\hline X2_5 & 0,831 & 0,235 & Valid \\
\hline X2_6 & 0,806 & 0,235 & Valid \\
\hline X2_7 & 0,827 & 0,235 & Valid \\
\hline X2_8 & 0,776 & 0,235 & Valid \\
\hline X2_9 & 0,824 & 0,235 & Valid \\
\hline X2_10 & 0,849 & 0,235 & Valid \\
\hline X2_11 & 0,873 & 0,235 & Valid \\
\hline X2_12 & 0,753 & 0,235 & Valid \\
\hline X2_13 & 0,772 & 0,235 & Valid \\
\hline X2_14 & 0,838 & 0,235 & Valid \\
\hline X2_15 & 0,646 & 0,235 & Valid \\
\hline
\end{tabular}

Sumber: Aplikasi komputer

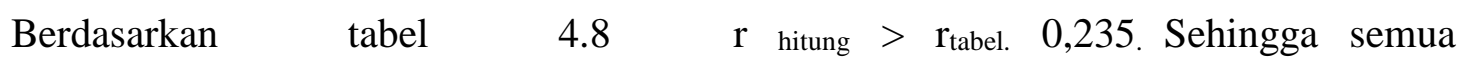
keputusan yang diambil bahwa item pertanyaan dinyatakan valid.

variabel tim kerja $\left(\mathrm{X}_{2}\right)$, memiliki nilai Berikut hasil uji validitas variabel kinerja karyawan (Y): 
Tabel 4.9 Hasil Uji Validitas Tim Kerja $\left(\mathrm{X}_{2}\right)$

\begin{tabular}{|c|c|c|c|}
\hline No Item & rxy & r tabel 5\% & Keterangan \\
\hline Y_1 & 0,809 & 0,235 & Valid \\
\hline Y_2 & 0,852 & 0,235 & Valid \\
\hline Y_3 & 0,865 & 0,235 & Valid \\
\hline Y_4 & 0,898 & 0,235 & Valid \\
\hline Y_5 & 0,891 & 0,235 & Valid \\
\hline Y_6 & 0,827 & 0,235 & Valid \\
\hline Y_7 & 0,879 & 0,235 & Valid \\
\hline Y_8 & 0,884 & 0,235 & Valid \\
\hline Y_9 & 0,893 & 0,235 & Valid \\
\hline Y_10 & 0,895 & 0,235 & Valid \\
\hline Y_11 & 0,803 & 0,235 & Valid \\
\hline Y_12 & 0,878 & 0,235 & Valid \\
\hline Y_13 & 0,892 & 0,235 & Valid \\
\hline Y_14 & 0,873 & 0,235 & Valid \\
\hline Y_15 & 0,763 & 0,235 & Valid \\
\hline
\end{tabular}

Berdasarkan tabel 4.9 keputusan yang diambil bahwa variabel tim kerja $\left(\mathrm{X}_{2}\right)$, memiliki nilai $\mathrm{r}$ hitung $>\mathrm{r}_{\text {tabel. }}$ 0,235.

Sehingga semua item pertanyaan dinyatakan valid.

\section{Hasil Penelitian Uji Reliabilitas}

Tabel 4.10 Hasil Uji Reliabilitas Variabel Rekrutmen (X1), Tim Kerja (X2) dan Kinerja Karyawan (Y)

\begin{tabular}{|c|c|c|c|}
\hline Variabel rxy & Cronbach's Alpha & $\mathrm{r}$ tabel 5\% $(70)$ & Ket \\
\hline X1 (Rekrutmen) & 0,913 & 0,235 & Reliabel \\
\hline X2 (Tim Kerja) & 0,959 & 0,235 & Reliabel \\
\hline Y (Kinerja Karyawan) & 0,975 & 0,235 & Reliabel \\
\hline
\end{tabular}

Sumber: Aplikasi komputer

Berdasarkan Tabel 4.10 hasil uji

reliabilitas dengan 3 variabel dan 45 
item pertanyaan ternyata ketiga Uji Normalitas Data

variabel memiliki cronbach's alpha $>r$

Hasil uji normalitas dengan

tabel 0,235 Sehingga dapat menggunakan aplikasi komputer

disimpulkan dari 45 item pertanyaan adalah sebagai berikut:

yang digunakan semuanya dapat

dikategorikan reliabel.

Tabel 4.11 Hasil Uji Normalitas

One-Sample Kolmogorov-Smirnov Test

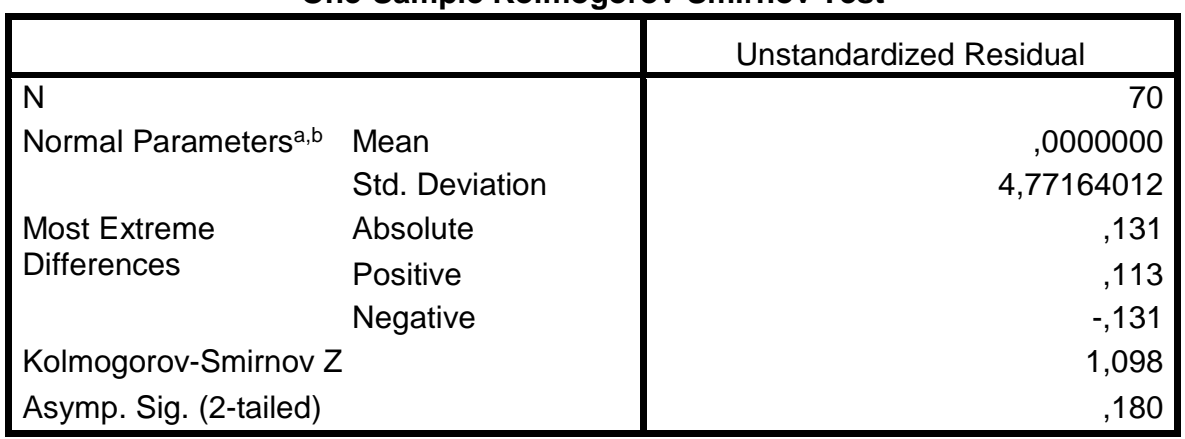

a. Test distribution is Normal.

b. Calculated from data.

Sumber: Data diolah

Dasar pengambilan keputusan, jika nilai signifikansi $>0,05$ maka data berdistribusi normal.

Berdasarkan tabel 4.19 terlihat bahwa nilai sig 0,180 > 0,05 maka data dalam penelitian ini

berdistribusi normal.

\section{Uji Homogenitas}

Dalam penelitian ini uji homogenitas dengan menggunakan One-Way ANOVA dengan aplikasi komputer.

Tabel 4.12

Uji Homogenitas Variabel Rekrutmen ( $\left.\mathrm{X}_{1}\right)$ terhadap Kinerja Karyawan (Y)

Test of Homogeneity of Variances

Kinerja Karyawan

\begin{tabular}{|c|c|c|c|}
\hline $\begin{array}{l}\text { Leven } \\
\text { e Statistic }\end{array}$ & $1^{d f}$ & $2^{d f}$ & g. $^{S i}$ \\
\hline 1,106 & 17 & 46 & $\begin{array}{r}, 3 \\
77\end{array}$ \\
\hline
\end{tabular}

Sumber: Data diolah 
Tabel 4.12 diatas menunjukkan disimpulkan bahwa data variabel bahwa nilai signifikansi variabel kinerja karyawan (Y) berdasarkan kinerja karyawan (Y) berdasarkan variabel rekrutmen ( $\left.\mathrm{X}_{1}\right)$ mempunyai variabel rekrutmen $\left(\mathrm{X}_{1}\right)=0,377>\quad$ variabel yang sama atau homogen.

0,05. Sehingga dapat

Tabel 4.13

Uji Homogenitas Variabel Tim kerja $\left(\mathrm{X}_{2}\right)$ terhadap Kinerja Karyawan (Y)

Test of Homogeneity of Variances Kinerja karyawan

\begin{tabular}{|r|r|r|r|}
\hline $\begin{array}{c}\text { Levene } \\
\text { Statistic }\end{array}$ & df1 & df2 & Sig. \\
\hline 1,169 & 13 & 46 &, 331 \\
\hline
\end{tabular}

diolah

Sumber: $\quad$ Data

Tabel 4.13 diatas menunjukkan data variabel kinerja karyawan

bahwa nilai signifikansi variabel berdasarkan variabel tim kerja $\left(\mathrm{X}_{2}\right)$

kinerja karyawan (Y) berdasarkan mempunyai variabel yang sama atau variabel tim kerja $\left(\mathrm{X}_{2}\right)=0,331>0,05 . \quad$ homogen

Sehingga dapat disimpulkan bahwa

\section{Uji Linearitas}

Tabel 4.14 Uji Linearitas Variabel $\mathrm{X}_{1}$ terhadap $\mathrm{Y}$

\begin{tabular}{|c|c|c|c|c|c|c|}
\hline \multicolumn{7}{|c|}{ ANOVA Table } \\
\hline & & $\begin{array}{l}\text { Sum of } \\
\text { Squares }\end{array}$ & $d f$ & $\begin{array}{l}\text { Mean } \\
\text { Square }\end{array}$ & $\mathrm{F}$ & Sig. \\
\hline \multirow{5}{*}{$\begin{array}{l}\text { Kinerja } \\
\text { karyawan } \\
\text { * } \\
\text { Rekrutmen }\end{array}$} & $\begin{array}{l}\text { Between (Combined) } \\
\text { Groups }\end{array}$ & 4240,429 & 23 & 184,366 & 7,272 & ,000 \\
\hline & Linearity & 3835,370 & 1 & 3835,370 & 151,282 & ,000 \\
\hline & $\begin{array}{l}\text { Deviation } \\
\text { from } \\
\text { Linearity }\end{array}$ & 405,059 & 22 & 18,412 & ,726 & ,790 \\
\hline & Within Groups & 1166,214 & 46 & 25,352 & & \\
\hline & Total & 5406,643 & 69 & & & \\
\hline
\end{tabular}

Sumber: Data diolah 
Berdasarkan uji liniearitas hubungan yang linier antara

diketahui nilai Sig.devitiation from Rekrutmen dengan Kinerja karyawan liniearity sebesar $0,790>0.05$, maka pada PT. Indoglobal Galang Pamitra.

dapat disimpulkan bahwa terdapat

Tabel 4.15 Uji Linearitas Variabel $\mathrm{X}_{2}$ terhadap $\mathrm{Y}$

ANOVA Table

\begin{tabular}{|c|c|c|c|c|c|c|c|}
\hline & $\begin{array}{l}\text { Sum of } \\
\text { Squares }\end{array}$ & $\mathrm{df}$ & $\begin{array}{l}\text { Mean } \\
\text { Square }\end{array}$ & $\mathrm{F}$ & Sig. \\
\hline \multirow{5}{*}{$\begin{array}{l}\text { Kinerja } \\
\text { Karyawan } \\
\text { * Tim } \\
\text { kerja }\end{array}$} & \multirow{3}{*}{$\begin{array}{l}\text { Between } \\
\text { Groups }\end{array}$} & (Combined) & 6997,455 & 23 & 304,237 & 13,893 &, 000 \\
\hline & & Linearity & 6427,468 & 1 & 6427,468 & 293,508 & , 000 \\
\hline & & $\begin{array}{l}\text { Deviation } \\
\text { from } \\
\text { Linearity }\end{array}$ & 569,987 & 22 & 25,908 & 1,183 & ,308 \\
\hline & \multicolumn{2}{|c|}{ Within Groups } & 1007,345 & 46 & 21,899 & & \\
\hline & \multicolumn{2}{|l|}{ Total } & 8004,800 & 69 & & & \\
\hline
\end{tabular}

Sumber: Data diolah

Berdasarkan uji liniearitas hubungan yang linier antara Tim kerja diketahui nilai Sig.devitiation from dengan Kinerja karyawan pada PT. liniearity sebesar $0,308>0.05$ maka Indoglobal Galang Pamitra.

dapat disimpulkan bahwa terdapat

\section{Analisis Regresi}

Tabel 4.16 Hasil olah data Regresi dan Korelasi

Coefficients $^{\mathrm{a}}$

\begin{tabular}{|c|c|c|c|c|c|c|}
\hline \multirow{2}{*}{\multicolumn{2}{|c|}{ Model }} & \multicolumn{2}{|c|}{ Unstandardized Coefficients } & \multirow{2}{*}{$\begin{array}{l}\text { Standardized } \\
\text { Coefficients } \\
\text { Beta }\end{array}$} & \multirow[b]{2}{*}{$\mathrm{t}$} & \multirow[b]{2}{*}{ Sig. } \\
\hline & & $\mathrm{B}$ & Std. Error & & & \\
\hline \multirow[t]{3}{*}{1} & (Constant) & $-2,246$ & 4,797 & &,- 468 & 641 \\
\hline & Rekrutmen &,- 081 & 155 &,- 052 &,- 518 & ,606 \\
\hline & Tim kerja & 1,144 & ,122 & ,940 & 9,362 &, 000 \\
\hline
\end{tabular}

a. Dependent Variable: Kinerja Karyawan

Sumber : Data diolah

Berdasarkan perhitungan persamaan regresi yang terbentuk

koefisien regresi tabel 4.16 diketahui adalah: 


$$
\mathrm{Y}=-2,246-0,081 \mathrm{X}_{1}+1,144 \mathrm{X}_{2}
$$

Berdasarkan persamaan tersebut

diketahui bahwa nilai koefisien

rekrutmen $(\mathrm{X} 1)=-0,81$ yang artinya

variabel X1 berpengaruh negatif.
Nilai koefisien tim kerja $(\mathrm{X} 2)=1,144$ yang artinya variabel X2 berpengaruh positif.

\section{Analisis Korelasi}

Tabel 4.30 Hasil Analisis Korelasi Variabel Rekrutmen $\left(X_{1}\right)$ dan Tim Kerja ( $\left.\mathrm{X}_{2}\right)$ Terhadap Kinerja Karyawan (Y)

\begin{tabular}{|r|r|r|r|r|}
\hline \multicolumn{5}{|c|}{ Model Summary } \\
\hline & $\mathrm{R}$ & R Square & $\begin{array}{c}\text { Adjusted } \\
\text { R Square }\end{array}$ & $\begin{array}{c}\text { Std. Error } \\
\text { of the } \\
\text { Estimate }\end{array}$ \\
\hline 1 &, 897 &, 804 &, 798 & 4,84233 \\
\hline
\end{tabular}

Sumber: Data dioalah

Berdasarkan tabel 4.12 diatas

diketahui $\quad \mathrm{R}=0,897$ terletak pada Koefisien Determinasi

interval (0,80-1000). Hal tersebut Pada tabel 4.30 dapat dilihat hasil berarti bahwa hubungan antara variabel koefisien determinasi sebesar 0,804 rekrutmen $\left(\mathrm{X}_{1}\right)$ dan tim kerja $\left(\mathrm{X}_{2}\right)$ atau $(80,4 \%)$ dan koefisien determinasi secara bersama-sama terhadap kinerja yang disesuaikan adalah 0,798 atau karyawan (Y) adalah sangat kuat dan (79,8\%). Dikarenakan dalam persamaan arah hubungan adalah positif karena regresi digunakan banyak variabel nilai $\mathrm{r}$ positif, berarti apabila $\mathrm{X}_{1}$ naik independen, maka koefisien yang maka $\mathrm{Y}$ juga naik dan sebaliknya digunakan untuk menjelaskan apabila $\mathrm{X}_{2}$ naik maka $\mathrm{Y}$ juga naik. persamaan ini adalah koefisien determinasi yang disesuaikan . 
$-0,518<\mathrm{t}$ tabel 1,998 sehinga dapat disimpulkan bahwa $\mathrm{Ha}_{1}$ ditolak dan $\mathrm{H}_{0}$ Hasil koefisien determinasi yang diterima yang berarti tidak ada disesuaikan sebesar 0,798 atau $79,8 \%$ pengaruh antara rekrutmen (X1) memberikan arti bahwa besarnya terhadap kinerja karyawan Y.

peranan rekrutmen dan tim kerja secara bersama-sama terhadap kinerja karyawan sebesar 79,8\%, sedangkan sisanya 20,2\% yang berperan adalah faktor-faktor lain yang tidak dimasukkan dalam penelitian ini.

Uji $T$ Variabel rekrutmen dengan

\section{Kinerja Karyawan}

Diketahui nilai Sig untuk

pengaruh $\mathrm{X} 1$ terhadap $\mathrm{Y}$ adalah sebesar 0,606 > 0,05 dan nilai t hitung

\section{Uji $T$ Variabel Tim Kerja dengan} Kinerja Karyawan

Nilai Sig untuk pengaruh X2 terhadap Y adalah sebesar $0,000<$ 0,05 dan nilai t hitung 9,362 > t tabel 1,998 sehingga dapat disimpulkan bahwa $\mathrm{Ha}_{2}$ diterima dan $\mathrm{Ho}_{2}$ di tolak yang berarti antara pengelolaan tim kerja yang efektif dengan kinerja karyawan pada PT. Indoglobal Galang Pamitra.

\section{Uji F}

Tabel 4.13 Hasil Uji F (Analisis Simultan) antara Rekrutmen $\left(\mathrm{X}_{1}\right)$ dan Tim Kerja $\left(\mathrm{X}_{2}\right)$ terhadap Kinerja Karyawan (Y)

\begin{tabular}{|ll|r|r|r|r|r|}
\hline \multicolumn{1}{|c|}{ Model } & & Sum of Squares & \multicolumn{1}{c|}{ df } & Mean Square & \multicolumn{1}{c|}{ F } & Sig. \\
\hline 1 & Regression & 6433,770 & 2 & 3216,885 & 137,191 &, $000^{\mathrm{a}}$ \\
& Residual & 1571,030 & 67 & 23,448 & & \\
& Total & 8004,800 & 69 & & & \\
\hline
\end{tabular}
a. Predictors: (Constant), Tim kerja, Rekrutmen
b. Dependent Variable: Kinerja Karyawan
Sumber: Data diolah 
Berdasarkan tabel 4.12 diketahui nilai signifikansi untuk pengaruh X1 dan X2 secara simultan terhadap $\mathrm{Y}$ adalah sebesar $0,000<0,05$ dan nilai $F$ hitung 137,191 > F tabel 3,13 sehingga dapat disimpulkan bahwa $\mathrm{Ha}_{3}$ diterima yang berarti terdapat pengaruh rekrutmen (X1) dan tim kerja (X2) secara simultan terhadap kinerja karyawan (Y).

\section{Kesimpulan dan Saran}

\section{Kesimpulan}

1. Terdapat pengaruh negatif yang tidak signifikan rekrutmen terhadap kinerja karyawan PT. Indoglobal Galang Pamitra Bogor

2. Terdapat pengaruh positif signifikan tim kerja terhadap kinerja karyawan PT. Indoglobal Galang Pamitra Bogor

3. Rekrutmen dan tim kerja secara bersama-sama memberikan pengaruh terhadap kinerja karyawan PT. Indoglobal Galang Pamitra Bogor

\section{Saran}

1. Sebaiknya manager melakukan tes kemampuan dan keahlian untuk dijadikan dasar penempatan kerja.

2. Untuk meningkatkan kemampuan karyawan pihak manajer perusahaan perlu mengadakan diklat (pendidikan dan pelatihan) setiap enam bulan untuk menambah pengetahuan dan keahlian karyawan dalam bekerja.

3. Sebaiknya manager membentuk tim pada setiap bagian dan menunjuk salah satu dari anggota tim untuk menjadi ketua. Tugas seoarang ketua ialah memantau, menegur, mengadakan musyawarah dan mufakat dalam menyelesaikan masalah, 
memberikan arahan dalam Darodjat, T. A. (2015). Pentingnya melaksanakan pekerjaan agar Budaya Kerja Tinggi dan Kuat dapat berjalan lancar dan Absolute. Bandung: PT. Refika membuat laporan kerja kepada Aditama.

manager.

Edison, E., Anwar, Y., \& Komariyah, I.

4. Untuk memotivasi karyawan agar tetap bekerja dengan baik, maka pimpinan perlu memberikan insentif \& kompensasi dan mengadakan rapat evaluasi kerja setiap dua minggu sekali.

5. Mengadakan tour gathering untuk menjalin keakraban antar sesama karyawan.

\section{DAFTAR PUSTAKA}

Athoillah, M. A. (2013). Dasar-dasar Manajemen. Bandung: Pustaka Setia.

Badriyah, M. (2015). Manajemen Sumber Daya Manusia. Bandung: CV. Pustaka Setia.
(2017). Manajemen Sumber Daya Manusia. Bandung: Alfabeta.

Firdaus, M. A. (2016). Metode Penelitian. Depok: Jelajah Nusa.

Handoko, H. T. (2015). Manajemen. Yogyakarta: BPFE Yogyakarta.

Mangkunegara, A. P. (2015). Manajemen Sumber Daya Manusia Perusahaan. Bandung: PT. Remaja Rosdakarya.

M.Nazir. (2014). Metodologi Penelitian. Bogor: Ghalia Indah.

Notoatmodjo, S. (2015). Pengembangan Sumber Daya Manusia. Jakarta: PT.Renika Cipta.

Priansa, D. J. (2017). Manajemen Kinerja Kepegawaian (Vol. 
$\begin{array}{llll}\text { Manajemen Sumber } \quad \text { Daya } & \text { Sujarweni. } & \text { (2014). }\end{array}$ Manusia Perusahaan. Bandung). Penelitian. Yogyakarta: Pustaka Bandung: CV Pondok Setia. Baru Express.

P.Robbins, S., \& A. Judge, T. (2014). Rahayu,S. (2017). Pengaruh Rekrutmen Perilaku Organisasi dan Kompensasi Terhadap Organizational Behavior. Kinerja Karyawan di Rumah Jakarta: Salemba Empat.

Sakit Trimitra Kabupaten Bogor.

Ridhotullah, S., \& Jauhar, M. (2015). Universitas Ibn Khaldun Bogor.

Pengantar Manajemen. Jakarta: Prestasi Pustakaraya.

Silaen, S. (2018). Metodologi Penelitian Sosial untuk Skripsi dan Tesis. Bogor: In Media.

Sinambela, L. P. (2016). Manajemen Sumber Daya Manusia: Membangun Tim Kerja yang Solid untuk Meningkatkan Kinerja. Jakarta: Bumi Aksara.

Sugiyono. (2015). Metode Penelitian Kuantitatif Kualitatif dan $R \& D$. Bandung: Alfabeta.
Sutrisno. (2017). Manajemen Sumber daya Manusia. Jakarta: Kencana.

Suwatno, \& Priansa, D. J. (2014). Manajemen SDM dalam Organisasi Publik dan Bisnis. Bandung: Alfabeta.

Umam, K. (2012). Perilaku Organisasi. Bandung: CV. Pustaka Setia.

Widodo, S. E. (2015). Manajemen Pengembangan Sumber Daya Manusia. Jakarta: Kencana.

\section{Artikel diunduh dari Internet}

Balqis, Zavia. 2016, Manajemen Sumber

Daya Manusia. [Internet].[2018, 
Agustus, 24, 03 :04 WIB] : tersedia

pada:

https://zaviabalqis.wordpress.com/20

16/04/30/manajemen-sumber-daya-

manusia/

Dudeja, Anshul. 2012, Jenis-jenis

Manajemen [Internet]. [Diunduh

2018, April, 20, 21:15 WIB] : tersedia

pada

http://stiebanten.blogspot.com/2011/

05/jenis-jenis-manajemen.html\#more

Lakoy, Amanda Carolina.2015. Pengaruh

Komunikasi, Kerjasama Kelompok dan Kreativitas terhadap Kinerja Karyawan pada Hotel Aryaduta Manado. [Internet]. [Diunduh: 2018, April, 21, 14:15 WIB]:tersedia pada http://jurnal.unmer.ac.id/index.php/j mdk/article/view/1313

Lawasi, Eva Silvani. 2017. Pengaruh Komunikasi, Motivasi dan Kerja Sama Tim terhadap Peningkatan Kinerja Karyawan. [Internet].
[Diunduh: 2018, April, 21, 14:15 WIB] : tersedia pada http://jurnal.unmer.ac.id/index.ph p/jmdk/article/view/1313

Maradut, Marpaung. 2014. Pengaruh Kepemimpinan dan Team Work terhadap Kinerja Karyawan di Koperasi Sekjen KEMDIKBUD Senayan Jakarta. [Internet]. [Diunduh 2018, April, 21, 13.00 WIB] : tersedia pada http://digilib.mercubuana.ac.id/mana ger/t\%21@file_artikel_abstrak/Isi_A rtikel_393539707348.pdf

Nicho, Eka. 2015, Tujuan Manajemen [Internet]. [Diunduh 2018, April, 20, 21:00 WIB] : tersedia pada http://nichonotes.blogspot.com/2015/ 02/tujuan-manajemen.html

Renaldo, Billy. 2016. Pengaruh Rekrutmen dan Seleksi terhadap Kinerja Karyawan pada PT. Bank Sulutgo Manado. [Internet]. 
Jurnal Ilmiah Inovator, Edisi September 2018

[Diunduh:2018, April, 21, 13:30

WIB] : tersedia pada

https://ejournal.unsrat.ac.id/imde

x.php/jbie/article/view/13628

Yusuf. 2018, Fungsi Manajemen Sumber

Daya Manusia Menurut Para

Ahli. [Internet]. [Diunduh 2018, Agustus, 24, 02:41 WIB] : tersedia pada http://jurnalmanajemen.com/fung

si-manajemen-sumber-daya-

manusia/

One-Way ANOVA dengan aplikasi komputer. 